\title{
Using team-based revision to prepare medical students for the prescribing safety assessment
}

This article was published in the following Dove Press journal:

Advances in Medical Education and Practice

\section{Samantha M Field \\ Nicholas J Burstow \\ David R Owen \\ Amir H Sam}

Medical Education Research Unit, Imperial College London, London, UK
Correspondence: Amir H Sam

Medical Education Research Unit, Imperial College London, 3rd Floor Hammersmith House, Hammersmith Hospital, Du Cane Road, London WI2 OHS, UK

Email a.sam@imperial.ac.uk
Background: The Prescribing Safety Assessment (PSA) is an online assessment of safe and effective prescribing, taken by final-year UK medical students. To prepare students for the PSA, we used a modified form of team-based learning, team-based revision (TBR), in which students consolidate previously learned prescribing knowledge and skills across a broad range of topics. We evaluated students' response to TBR and their perceptions of team working.

Methods: Eight TBR sessions based on the PSA blueprint were conducted over two days by three faculty members for final year medical students. During TBR sessions, students worked in small groups answering individual multiple-choice questions, followed by group multiplechoice questions. They subsequently answered open-ended questions in their groups, with answers written on a drug chart to increase authenticity. Students completed surveys using Likert-type items to determine views on TBR and their confidence in prescribing.

Results: The majority of respondents agreed that the sessions were useful for preparation both for the PSA (82\%) and Foundation Year 1 (78\%). 92\% agreed that using drug-charts aided learning. Prescribing confidence increased significantly after TBR (median pre-TBR: 2, post-TBR: $5, p<0.0001)$. TBR significantly improved attitudes towards "team experience" $(p<0.001)$, "team impact on quality of learning" $(p<0.01)$ and "team impact on clinical reasoning ability" $(p<0.001)$.

Conclusions: Team-based revision is a resource-efficient addition to undergraduate prescribing teaching and can help with preparation for the PSA. A short course of TBR was effective in influencing students' attitudes towards teamwork.

Keywords: team-based learning, team-based revision, prescribing safety assessment

\section{Introduction}

The ability to prescribe safely and effectively is a key learning outcome for undergraduate education. The Prescribing Safety Assessment (PSA) has been developed by the British Pharmacological Society and Medical Schools Council to enable final-year medical students to demonstrate that the required outcomes have been met. ${ }^{1}$ The advent of electronic health records and electronic prescriptions that can only be generated by qualified doctors has introduced new challenges in undergraduate teaching and practice of this key competency.

Team-based learning (TBL) offers a student-centered approach to teaching that maintains individual accountability alongside teamwork and active learning. ${ }^{2,3}$ TBL provides a "flipped classroom" approach, whereby students acquire knowledge in their own time in preparation for the teaching session, and class time with the instructor is used to develop teamwork and higher order skills like problem solving 
and decision-making. ${ }^{4}$ TBL has demonstrated results comparable to lecture-based teaching, is particularly effective in improving academic performance of weaker students, ${ }^{5-7}$ and is well received by medical students and staff. ${ }^{5-8}$ During the final year at medical school, a particular emphasis is placed on readiness to practice, with a focus on consolidation of knowledge and clinical skills, and development of non-clinical skills. The interactive nature of TBL, its focus on non-clinical skills development, and the active learning component, mean it is particularly well suited for final year students. Team-based learning has been shown to promote student engagement, ${ }^{9}$ as well as professionalism, teamwork and communication skills. ${ }^{4}$ In addition, TBL has been shown to be effective in delivering pharmacology education. ${ }^{3,7,10,11}$

TBL comprises three phases: phase 1 involves self-directed learning on the contents to be discussed later in the classroom. Phase 2 is split into two sub-sections: the first involves individual readiness assurance tests, where knowledge acquired in phase 1 is tested. The second involves the same readiness assurance test, this time taken as a group, alongside the opportunity to discuss with the instructor. Phase 3 involves higher levels of learning through using teamwork to tackle more complex course concepts. ${ }^{3}$ TBL is used to aid learning new content for a limited number of topics during each session. We developed a modified form of TBL, team-based revision (TBR), to enable students to revisit and consolidate previously learned information across a broad range of topics. The medical curriculum at Imperial College London encompasses two science-focused years (Years 1 and 2) and three years of clinical placements (Years 3, 5 and 6). During Year 4, students work towards a BSc by undertaking a series of modules and a supervised research project. The student body comprises primarily undergraduates, with a proportion of postgraduates. We examined the utility of TBR in preparing final year medical students for the PSA. We evaluated the acceptability of TBR, and whether a short course of TBR can influence students' and attitudes towards teamwork. As a major focus of the final year curriculum is to improve "readiness to practice", we also used a basic scale to judge whether TBR could influence confidence in prescribing.

\section{Methods}

\section{TBR design and participants}

The study was approved by the Medical Education Ethics Committee at Imperial College London. Four $1.5 \mathrm{hr}$ PSA- based TBR sessions were delivered for 201 final year medical students at Imperial College School of Medicine over two days, facilitated by three faculty members. TBR sessions had the same structure as TBL except for phase 1: rather than giving students new information to learn in their own time before the session, TBR made use of students' pre-existing knowledge acquired during clinical placements.

Material for the sessions was developed by the Imperial College School of Medicine faculty, and was based on the Prescribing Safety Assessment (PSA) blueprint consisting of eight domains: Prescribing, Prescription Review, Planning Management, Providing Information, Calculation Skills, Adverse Drug Reactions, Drug Monitoring, and Data Interpretation within seven clinical settings: Medicine, Surgery, Elderly Care, Paediatrics, Psychiatry, Obstetrics and Gynecology and General Practice. ${ }^{12}$ TBR questions were written in a similar style to reflect the problem-solving and clinical reasoning that the assessment requires, and questions were reviewed by the Head of Year 6 Assessment and the Lead for Clinical Pharmacology and Therapeutics to ensure accuracy and relevance. Sessions took place at the start of students' final year, seven months prior to sitting the PSA. As the students did not have extensive prior experience with TBL, we elected to hold the sessions at the beginning of their revision period rather than towards the end to reduce anxiety. The sessions were not compulsory, and all students who were present at the session completed the evaluation.

Students worked in teams of 6-8. During the TBR sessions, students first received a Multiple-Choice Question (MCQ) test using a cloud-based tool (SurveyMonkey). After answering the questions individually, students completed the same questions working as a group, using "instant feedback assessment technique" scratch cards. Subsequently facilitators led group discussions about the answers. Students had access to the British National Formulary (BNF) throughout the sessions.

Students were then given five clinically orientated cases and asked to prescribe appropriate medications on a drug chart as a group. All groups worked on the same questions. Students were subsequently taken through the correct answers by the facilitators.

\section{Student questionnaires}

All students were asked to complete a pre- and post-TBR questionnaire. The questionnaires were completed on 
iPads using SurveyMonkey to collect data, and written consent was gained from each participant prior to completing the survey. The questionnaire comprised two sections. The first section recorded self-rated confidence in prescribing on a 10-point scale, with 1 indicating "Not confident" and 10 indicating "Very confident". The second section was a modified validated instrument developed to assess attitudes towards teamwork after TBR among medical students. It used a five-point Likert scale ranging from Strongly Disagree (1) to Strongly Agree (5) to assess teamwork-related attitudes in four broad domains (Table 1). ${ }^{13}$

\section{Statistical analyses}

Wilcoxon signed rank test was used to analyze paired data using PRISM Version 7.04 (GraphPad Software, Inc., San Diego, CA, USA).

\section{Results}

\section{Acceptability of TBR and impact on prescribing confidence}

Ninety-eight students responded to the questionnaire about their perceptions of TBR as a learning method after the course (Figure 1). $82 \%$ of medical students agreed/ strongly agreed that TBR sessions helped their preparation for the PSA. $78 \%$ of medical students agreed/strongly agreed that TBR sessions helped their preparation for foundation year 1. $92 \%$ of medical students agreed/ strongly agreed that the use of drug charts during TBR was useful for their learning. Lower proportions of students agreed/strongly agreed that TBR was a good way of learning pharmacology $(44 \%)$ or would be useful for learning in other subjects (35\%). Self-rated prescribing confidence increased significantly after TBR (median pre-TBR: 2, post-TBR: $5, p<0.0001)$.

\section{Impact of TBR on students' attitudes to teamwork}

Overall, 201 students completed the pre-TBR questionnaire, and 98 students completed the post-TBR questionnaire. Eighty-six students completed both the pre- and post-TBR questionnaires. The demographics of those who completed only the pre-TBR questionnaire and those who completed both were comparable. In both groups, the majority were aged 23-24 years old $(72.1 \%$ of those who completed the pre-TBR questionnaire vs $69.8 \%$ of those who completed both the pre-TBR and post-TBR questionnaires). There was a higher proportion

Table I The questionnaire used to assess attitudes towards teamwork among medical students in four broad domains

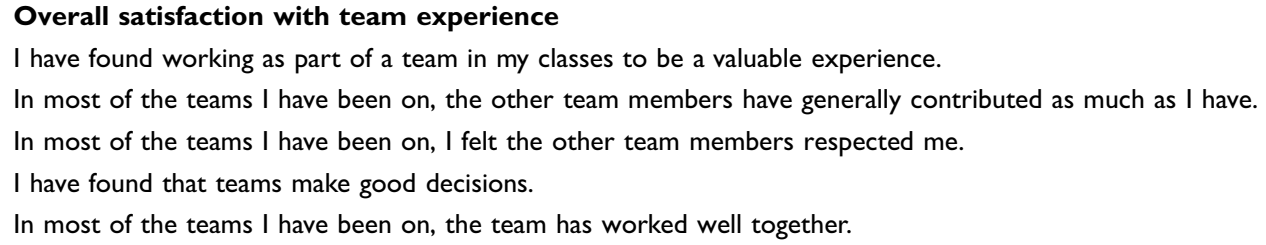

Team impact on quality of learning

I have found teamwork to be a productive use of course time.

I have found that teams help me learn course material more than if I just studied alone.

I have learned more in courses where I have been a member of a team.

I have found being part of a team improves my course grades.

\section{Professional development}

I have found that working with a team helps me develop skills in working with others.

I have found that working with a team has helped me develop cooperative leadership skills.

I have found that working with a team has helped me develop more respect for the opinion of others.

I have found that working with a team has enhanced my readiness for the hospital environment

\section{Team impact on clinical reasoning ability}

I have found that being on a team has helped me become better at problem solving.

Being part of a team discussion has improved my ability to think through a problem.

I feel that team-based learning has improved my clinical reasoning skills

Note: Adapted from Parmelee DX, DeStephen D, Borges NJ. Medical students' attitudes about team-based learning in a pre-clinical curriculum. Med Educ Online. 2009; I4:I. Creative Commons license and disclaimer available from: http://creativecommons.org/licenses/by/4.0/legalcode. ${ }^{13}$ 

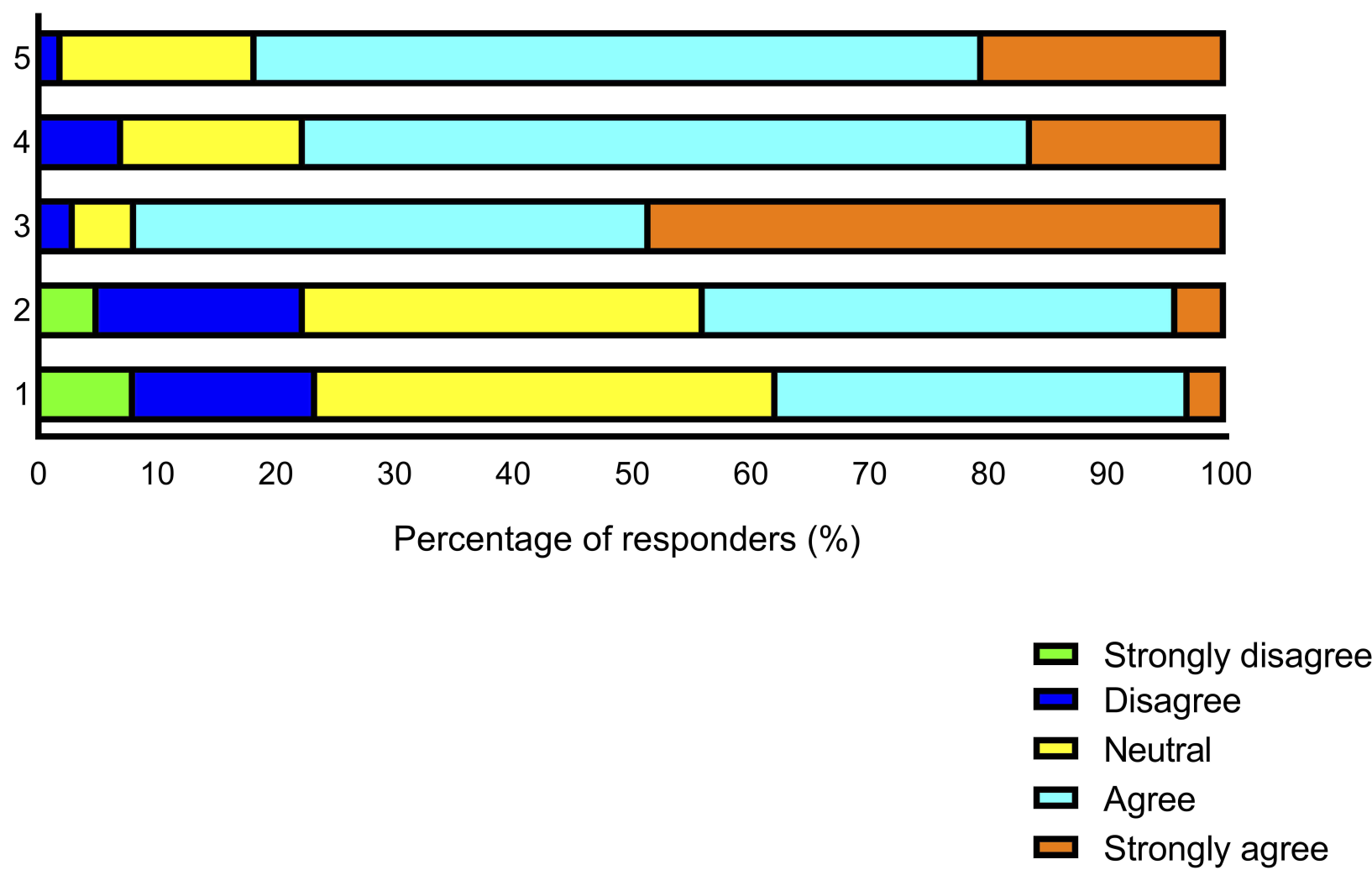

Figure I The percentage of responders selecting each point on a 5-point Likert scale are shown for each of five statements about team-based revision (TBR). I. TBR would be useful in learning other subjects. 2. TBR is a good way of learning pharmacology. 3. The use of drug charts during TBR was useful for my learning. 4. TBR sessions have helped in my preparation for foundation year I. 5. TBR sessions have helped my preparation for the prescribing safety assessment (PSA).

of females in the group that completed both pre-TBR and post-TBR questionnaires (54.6\% vs $49.7 \%)$, and a higher proportion of postgraduate students in the group who completed both pre-TBR and post-TBR questionnaires (15.1\% vs $12.9 \%)$. For the group that completed both questionnaires, the impact of TBR on students' attitudes to teamwork across four domains is shown in Table 2. Overall, there was a significant increase in students' attitudes towards teamwork in the areas of Satisfaction with

Table 2 The impact of team-based revision (TBR) on students' attitudes to teamwork across four domains

\begin{tabular}{|l|l|l|l|}
\hline & $\begin{array}{l}\text { Pre- } \\
\text { TBR }\end{array}$ & $\begin{array}{l}\text { Post- } \\
\text { TBR }\end{array}$ & p-value \\
\hline $\begin{array}{l}\text { Overall satisfaction with team } \\
\text { experience }\end{array}$ & 3.77 & 3.93 & $<0.001$ \\
\hline $\begin{array}{l}\text { Team impact on quality of } \\
\text { learning }\end{array}$ & 3.10 & 3.32 & $<0.01$ \\
\hline Professional development & 3.74 & 3.76 & 0.86 \\
\hline $\begin{array}{l}\text { Team impact on clinical reason- } \\
\text { ing ability }\end{array}$ & 3.45 & 3.69 & $<0.001$ \\
\hline
\end{tabular}

Team Experience $(p<0.001)$, Team Impact on Quality of Learning $(p<0.01)$ and Team Impact on Clinical Reasoning Ability $(p<0.001)$ after TBR sessions. We did not see a significant change in attitude towards Professional Development after TBR sessions.

\section{Discussion}

A recent systematic literature review suggested that medical students have a general lack of preparedness, selfconfidence, knowledge and skills in prescribing. ${ }^{14} \mathrm{We}$ have shown that a short course of TBR delivered by three faculty members for 201 students can lead to a significant improvement in students' confidence in prescribing.

It has previously been reported that students view TBL more positively once it has been embedded in the curriculum over a three-year period. ${ }^{8}$ We were interested to see how students' perceptions of TBR would change after a two-day course, to assess its acceptability in the short term. The majority of respondents agreed that the TBR sessions helped their preparation for both the PSA and for work as newly qualified doctors. Along with the positive 
response to the use of drug charts, this implies that this method of interactive revision is considered helpful for exam preparation and readiness to practice. The students' response to the usefulness of TBR for learning pharmacology was more variable. This was in keeping with the primary objective of the TBR to draw on the prescribing knowledge and skills learned across a broad range of topics by final year students rather than introducing a new topic in pharmacology. In future, it would be useful to compare how students would feel about the utility of TBL in learning pharmacology and other subjects, if they were exposed to new material through this learning method rather than using it as a tool to consolidate learning.

Extended courses of TBL have been shown to improve perceptions of teamwork in medical students. ${ }^{13}$ Interestingly, our two-day TBR course delivered similar findings, positively impacting students' perceptions towards teamwork in all but one the assessed domains. We did not see a significant impact within the "professional development" category, suggesting that this area may require longer periods of collaborative learning to change students' perceptions.

Our study was limited by inclusion of students from a single medical school, and a single year group. Furthermore, not all students completed both questionnaires. This may have biased the questionnaire results, not reflecting the opinions of the entire student body. It may be that TBR suits a certain cohort of students, and more work needs to be done to understand this further. Finally, another limitation of this study was the use of a scale to measure self-confidence, which had not previously been validated in this setting. As students increasingly seek active learning methods, the utility of TBR to provide a high level of engagement should be further evaluated. The PSA has also been suggested to be relevant to pharmacy trainees ${ }^{15}$ and thus TBR may also be of value in undergraduate pharmacy education.

Our study found that students responded particularly favourably to the use of drug charts during the sessions. The educational benefits of open-ended questions are well documented. ${ }^{16}$ Open-ended questions can be a useful addition to TBL, ${ }^{17}$ and our results support this. Future work should evaluate the use of online-drug charts for teaching purposes and sophisticated automated free-text marking systems.

In conclusion, our work has demonstrated TBR to be an acceptable, resource efficient method to improve medical student confidence in prescribing. Furthermore, a short course of TBR can be effective in influencing attitudes toward teamwork.

\section{Disclosure}

The authors report no conflicts of interest in this work.

\section{References}

1. Maxwell SRJ, Cameron IT, Webb DJ. Prescribing safety: ensuring that new graduates are prepared. Lancet. 2015;385:579-581. doi:10.1016/S0140-6736(14)62339-4

2. Parmelee D, Michaelsen LK, Cook S, Hudes PD. Team-based learning: a practical guide: AMEE guide no. 65. Med Teach. 2012;34: e275-e287.

3. Zgheib NK, Simaan JA, Sabra R. Using team-based learning to teach clinical pharmacology in medical school: student satisfaction and improved performance. J Clin Pharmacol. 2011;51:1101-1111. doi: $10.1177 / 0091270010383858$

4. Zgheib NK, Dimassi Z, Bou Akl I, Badr KF, Sabra R. The long-term impact of team-based learning on medical students' team performance scores and on their peer evaluation scores. Med Teach. 2016;38:1017-1024. doi:10.3109/0142159X.2015.1035054

5. Nieder GL, Parmelee DX, Stolfi A, Hudes PD. Team-based learning in a medical gross anatomy and embryology course. Clin Anat. 2005;18:56-63. doi:10.1002/(ISSN)1098-2353

6. Conway SE, Johnson JL, Ripley TL. Integration of team-based learning strategies into a cardiovascular module. Am J Pharm Educ. 2010;74:35. doi:10.5688/aj740235

7. Zgheib NK, Simaan JA, Sabra R. Using team-based learning to teach pharmacology to second year medical students improves student performance. Med Teach. 2010;32:130-135.

8. Davidson LK. A 3-year experience implementing blended TBL: active instructional methods can shift student attitudes to learning. Med Teach. 2011;33:750-753. doi:10.3109/0142159X.2011.599894

9. Hunt DP, Haidet P, Coverdale JH, Richards B. The effect of using team learning in an evidence-based medicine course for medical students. Teach Learn Med. 2003;15:131-139. doi:10.1207/ S15328015TLM1502_11

10. Bou Akl I, Ghaddar F, Sabra R, et al. Teaching clinical pharmacology using team-based learning: a comparison between third- and fourthyear medical students. J Clin Pharmacol. 2012;52:1806-1814. doi: $10.1177 / 0091270011428986$

11. Rao YK, Shenoy GK. Introducing team based learning in undergraduate pharmacology. Indian $J$ Pharmacol. 2013;45:102-103. doi:10.4103/0253-7613.106450

12. Maxwell SRJ, Coleman JJ, Bollington L, Taylor C, Webb DJ. Prescribing safety assessment 2016: delivery of a national prescribing assessment to 7343 UK final-year medical students. $\mathrm{Br} \mathrm{J}$ Clin Pharmacol. 2017;83:2249-2258. doi:10.1111/bcp.13319

13. Parmelee DX, DeStephen D, Borges NJ. Medical students' attitudes about team-based learning in a pre-clinical curriculum. Med Educ Online. 2009;14:1. doi:10.3885/meo.2009.Res00280

14. Brinkman DJ, Tichelaar J, Graaf S, Otten RHJ, Richir MC, van Agtmael MA. Do final-year medical students have sufficient prescribing competencies? A systematic literature review. $\mathrm{Br} J$ Clin Pharmacol. 2018;84:615-635. doi:10.1111/bcp.13491

15. Hardisty J, Davison K, Statham L, Fleming G, Bollington L, Maxwell S. Exploring the utility of the prescribing safety assessment in pharmacy education in England: experiences of preregistration trainees and undergraduate (MPharm) pharmacy students. Int J Pharm Pract. 2019;27(2):207-213. doi:10.1111/ ijpp. 12479

16. Sam AH, Field SM, Collares CF, et al. Very-short-answer questions: reliability, discrimination and acceptability. Med Educ. 2018;52:447455. doi:10.1111/medu.2018.52.issue-4

17. Badgett RG, Stone J, Collins TC. The importance of free-text responses in team-based learning design. Acad Med. 2014;89:1578. doi:10.1097/ACM.0000000000000512 


\section{Publish your work in this journal}

Advances in Medical Education and Practice is an international, peerreviewed, open access journal that aims to present and publish research on Medical Education covering medical, dental, nursing and allied health care professional education. The journal covers undergraduate education, postgraduate training and continuing medical education

including emerging trends and innovative models linking education, research, and health care services. The manuscript management system is completely online and includes a very quick and fair peer-review system. Visit http://www.dovepress.com/testimonials.php to read real quotes from published authors.

Submit your manuscript here: http://www.dovepress.com/advances-in-medical-education-and-practice-journal 